\title{
The association of female and male infertility with telomere length (Review)
}

\author{
ELENI VASILOPOULOS $^{1 *}$, PERSEFONI FRAGKIADAKI ${ }^{2,3^{*}}$, CHARIKLEIA KALLIORA $^{4 *}$, DOMNIKI FRAGOU ${ }^{5}$, \\ ANCA OANA DOCEA ${ }^{6}$, ELENA VAKONAKI ${ }^{2,3}$, DIMITRIS TSOUKALAS ${ }^{2,7,8}$, DANIELA CALINA ${ }^{8}$, \\ ANA MARIA BUGA ${ }^{9}$, GEORGE GEORGIADIS ${ }^{10}$, CHARALAMPOS MAMOULAKIS ${ }^{10}$, \\ ANTONIOS MAKRIGIANNAKIS ${ }^{11}$, DEMETRIOS A. SPANDIDOS ${ }^{12}$ and ARISTIDIS TSATSAKIS ${ }^{2,3}$
}

${ }^{1}$ Department of Biology, Temple University, Philadelphia, PA 19122, USA; ${ }^{2}$ Laboratory of Toxicology, Medical School, University of Crete, 71003 Heraklion; ${ }^{3}$ Spin-Off Toxplus S.A., 71601 Heraklion, Greece; ${ }^{4}$ Department of Obstetrics and Gynecology, University of Pennsylvania, Philadelphia, PA 19104, USA; ${ }^{5}$ Laboratory of Forensic Medicine and Toxicology, School of Medicine, Aristotle University of Thessaloniki, 54124 Thessaloniki, Greece; ${ }^{6}$ Department of Toxicology,

University of Medicine and Pharmacy of Craiova, 200349 Craiova, Romania; ${ }^{7}$ Metabolomic Medicine Clinic, Health Clinics for Autoimmune and Chronic Diseases, 10674 Athens, Greece; Departments of ${ }^{8}$ Clinical Pharmacy, and ${ }^{9}$ Biochemistry, University of Medicine and Pharmacy of Craiova, 200349 Craiova, Romania; Departments of ${ }^{10}$ Urology, and ${ }^{11}$ Obstetrics and Gynecology, University General Hospital of Heraklion, Medical School, University of Crete; ${ }^{12}$ Laboratory of Clinical Virology, School of Medicine, University of Crete, 71003 Heraklion, Greece

Received April 16, 2019; Accepted May 24, 2019

DOI: $10.3892 / \mathrm{ijmm} .2019 .4225$

\begin{abstract}
Telomere length (TL) has long been associated with aging, as telomeres serve as protective caps of chromosomes, and are thus deeply involved in the preservation of genome integrity and are vital to cellular functions. Traditionally, a strong link connects aging and infertility in both sexes, with an earlier onset in females. Over the past decade, telomeres have attracted increasing attention due to the role they play in fertility. In this review, we investigated the potential positive or
\end{abstract}

Correspondence to: Professor Aristidis Tsatsakis, Laboratory of Toxicology, Medical School, University of Crete, Voutes, 71003 Heraklion, Greece

E-mail: tsatsaka@uoc.gr

${ }^{*}$ Contributed equally

Abbreviations: ART, assisted reproductive techniques; GJIC, gap-junctional intercellular communication; GTL, granulosa cell telomere length; HGSC, high-grade serous carcinoma; IVF, in vitro fertilization; LTL, leukocyte telomere length; OOI, occult ovarian insufficiency; PCOS, polycystic ovary syndrome; POI, primary ovarian insufficiency; Q-FISH, quantitative fluorescent in situ hybridization; RT-PCR, reverse transcription-polymerase chain reaction; STIC, serous tubal intraepithelial carcinoma; STL, sperm telomere length; TA, telomerase activity; TEP1, telomerase-associated protein 1; TERT, telomerase reverse transcriptase; TL, telomere length; DOR, diminished ovarian reserve

Key words: aging, female infertility, fertility, male infertility, telomere shortening negative association between relative TL and different factors of female and male infertility. A systematic search of the PubMed database was conducted. Out of the 206 studies identified, 45 were reviewed as they fulfilled the criteria of validity and relevance. Following an analysis and a comparison of the study outcomes, several clear trends were observed. The majority of female infertility factors were associated with a shorter TL, with the exception of endometriosis, premature ovarian failure and clear cell carcinoma that were associated with a longer TL and polycystic ovary syndrome (PCOS), which revealed conflicting results among several studies, leading to ambiguous conclusions. Male infertility factors were associated with a shorter TL. Although this review can provide an outline of general trends in the association of TL with infertility factors, further epidemiological and original research studies are required to focus on investigating the basis of these varying lengths of telomeres.

\section{Contents}

1. Introduction

2. Telomere length and female infertility

3. Telomere length and male infertility

4. Conclusions and future perspectives

\section{Introduction}

The irreversible process of aging is marked by a decline in the body's physiological functions and adaptation ability. One of the systems impaired by this process is the reproductive 
system. According to recent publications, infertility affects an estimated $15 \%$ of couples globally (1). In 2016, almost 66,000 births in the United States were achieved from the assisted reproduction techniques application (2). According to the statistics of the Society for Assisted Reproductive Technology (SART), 241,570 cycles for egg retrieval, frozen embryo transfer and frozen egg thawing were performed (3). Despite common belief that infertility factors are usually associated with only the female sex, male factors have been found to be solely responsible for $20-30 \%$ of infertility cases and to contribute to $50 \%$ of the cases overall (4). The deleterious effects of reproductive aging affect both males and females; however, an earlier onset is observed among females, as a sharp decrease in fertility is reported after the age of 35 (5). The process of aging is strongly influenced by genetics, as well as environmental and lifestyle factors. Currently, the aging process is divided into two major components, biological and chronological age, which can differ for the same individual. Biological aging can be calculated by telomere length (TL) and DNA methylation levels (6). Telomeres are the end parts of linear chromosomes and consist of many tandem repeats of 5'-TTAGGG-3'. When cells divide, they are unable to replicate approximately 50 base pairs to the end of each chromosome. This leads to the progressive shortening with each round of cell division (7) (Fig. 1), resulting in cell proliferation arrest and cell senescence. This mechanism is the leading cause of aging and age-related chronic diseases. In 2009, Blackburn, Greider and Szostak received the Nobel Prize for discovering the protective role of telomeres and the enzyme telomerase on chromosomes. These highly significant discoveries opened the way for researchers to further explore the role of telomere shortening in aging. By the construction of a biological age equation, the measuring of TL has come to be a calculating tool for the biological age of the body, including, but not limited to gonadal age $(8,9)$ thus more accurately predicting the fertility status. Recently, a database was published named 'BIOTEL version 2.4', Telomere Length Database Project (TLDP), a semi-automated worksheet that calculates a wide range of TL statistics and it is a useful tool with applications in research on telomere biology, and in biological age estimation (10).

Both genetic signature and external factors can decrease the gonadal pool and can thus subsequently increase male and female infertility, despite a favorable chronological age (11). Specifically, such external factors include human exposure to chemicals and pesticides used in agriculture and industry that act as endocrine disruptors (EDs) (11-15), dysregulating normal reproductive system functions (16-18), as well as drug abuse (19).

It has been claimed that epigenetic factors, such as nutrition, exercise and tobacco can also affect the rate at which telomeres shorten and the risk of developing chronic diseases. Notably, nutrition supplements have been shown to benefit the length of short telomeres (20).

A method of delaying the aging process has been proposed to be telomerase activation (21). Telomerase activation by natural molecules has been suggested to be potent in anti-aging and the treatment of related diseases. Telomerase activation can be achieved through natural molecules, synthetic molecules, and genetic manipulation and intervention. Recently, supplements and natural extracts were tested for their capacity to enhance telomerase activity (TA) in human peripheral blood mononuclear cells. It was demonstrated that formulations containing Astragalus extract activate telomerase to higher levels than the reported levels, indicating that the synergistic effects of nutrients and natural compounds can activate telomerase and can produce more potent formulations (22). One way in which telomerase can repair short or dysfunctional telomeres is by the addition of nucleotides at their ends, further stabilizing them. Indeed, TL and TA have been proposed as biomarkers of aging and studies have investigated their implications in other chronic diseases $(23,24)$.

In an effort to identify the causes of age-related infertility, researchers have managed to link the aging process to genomic and epigenomic alterations, DNA damage and oxidative stress (25). However, several human studies, which will be further reviewed below, have attempted to investigate the role of telomeres in infertility on a wider spectrum, by indicating the relative TL in individuals with varying types of infertility.

The aim of this review was to elucidate the potential positive or negative association between relative TL and different factors of infertility, namely male factor, tubal factor, polycystic ovary syndrome (PCOS), ovarian reserve, endometriosis, anovulation, cancer related infertility and idiopathic infertility.

The Medline [Ovid MEDLINE(R) In-Process \& Other Non- Indexed Citations and Ovid MEDLINE(R) (1946 to February, 2018)] electronic database was searched to detect all publications focusing on the association of TL with human female and male infertility. The comprehensive literature was searched in accordance with the Preferred Reporting Items for Systematic Reviews and Meta-analyses (PRISMA) statement (26), using the following literature search strategies: i) Telomeres OR TL AND fertility OR infertility; ii) Male Factor: telomere AND (idiopathic male infertility OR oligospermia OR azoospermia OR hypospermia OR teratospermia OR aspermia OR asthenozoospermia OR necrozoospermia OR leukospermia); iii) Tubal Factor: Telomere AND (hydrosalpinx OR fallopian tube OR tubal factor); iv) PCOS: Telomere AND PCOS; v) Ovarian Reserve: Telomere AND (ovary OR ovarian reserve); vi) Endometriosis: Telomere AND endometriosis; vii) Anovulation: Telomere AND (anovulation OR ovulation); viii) Unknown: Telomere AND (unexplained infertility OR idiopathic infertility).

After excluding duplicates, titles and abstracts were screened for relevance, marked by a link between infertility cause and relative TL (longer or shorter). Two review authors (E. Vasilopoulos and C. Kalliora) independently scanned the title or the abstract content, or both, of every record retrieved to determine which studies should be assessed further and extracted all data. Citations in conference abstract form, review articles, animal studies, editorials, and non-English language articles were excluded.

For each of these studies, it was determined whether a positive or negative association between the infertility factor they are focused on and TL is shown. This specific infertility factor was noted for each study, along with other important information (sex, relative TL and the method of measurement, population size, population age, population region, sample type and conclusion). The studies were further organized by infertility factor, allowing collective conclusions to be drawn. A total of 45 studies showing either a positive or negative association between male or female infertility and TL were included in the present review (Fig. 2). 

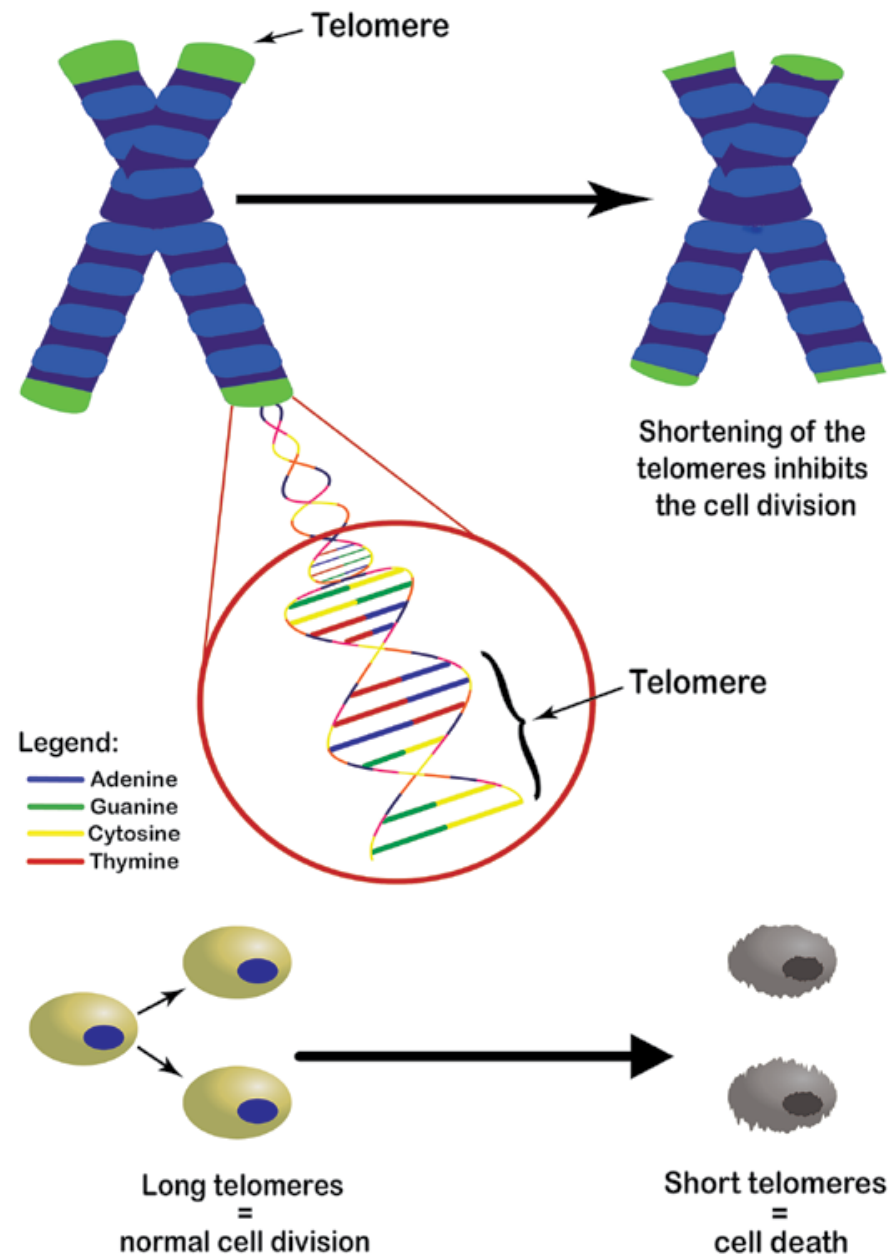

Figure 1. Role of telomeres in cellular division. Every cycle of cell division leads to the progressive shortening of telomeres. Shortened telomeres ultimately are unable to divide further and are led to senescence and cell death.

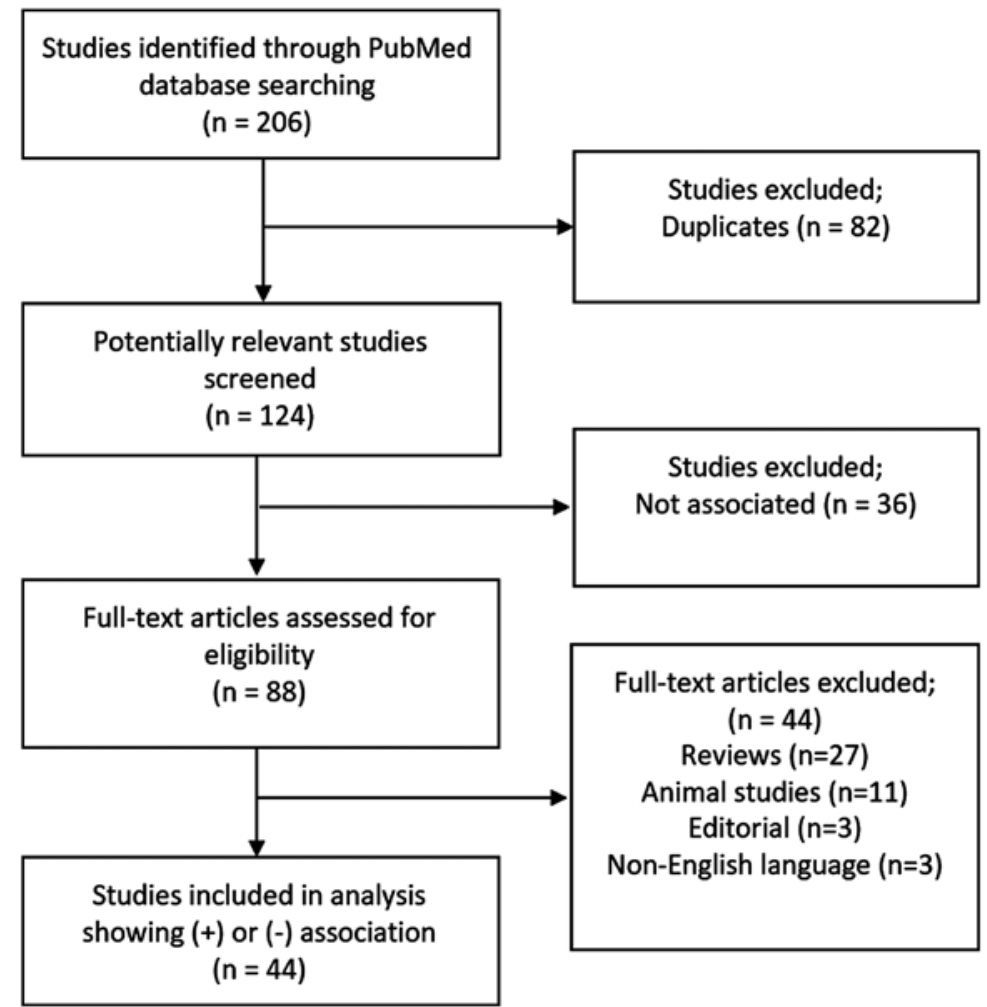

Figure 2. PRISMA flow diagram for the identification and selection of studies. 


\section{Telomere length and female infertility}

It is known that shorter telomeres are associated with a range of chronic diseases, such as cardiovascular disease (CAD), stroke, cancer, arthritis, osteoporosis, diabetes type 2, hypertension, mental diseases, chronic obstructive pulmonary disease and dementia (27-31). Apart from natural, chronological aging, telomere shortening can be influenced by physical activity, body mass index (BMI), hormone replacement therapy, smoking, chronic inflammation, oxidative stress, dietary antioxidants and vitamins. Previous studies have found that women following a healthy lifestyle have longer telomeres (32).

A fundamental factor for the achievement of early pregnancy is the successful implantation of the embryo. A window of implantation is in the mid-secretory phase of the menstrual cycle, which involves the dominant action of progesterone with maximum cell differentiation. This period is also associated with the lowest endometrial telomerase activity (TA) and the shortest mean TL, suggesting a requirement of a low endometrial TA for the establishment of an early pregnancy $(33,34)$. This suppression of TA in the endometrium of fertile women has been proposed as a necessary process in order to allow endometrial cells to undergo differentiation with cellular apoptosis/senescence required to make space for the invading embryo (33-35). The underlying mechanisms for this regulation and differential (dys)regulation are still under research.

Several studies have thoroughly investigated the association of female infertility with TL. The majority of studies exploring the association between female infertility factors and TL are outlined in Table I and have revealed a positive association, while only 3 have revealed negative association (36-38). Of the 21 positively associated studies, 11 studies demonstrated a shorter TL, while 10 demonstrated a longer TL. Specifically, a positive correlation was observed between a short TL and oocyte maturation, parity, a disrupted gap-junctional intercellular communication (GJIC) in stromal cells and oocytes of poor quality (39-42). Barha et al measured TL in a group of 75 Kaqchikel Mayan women over a 13-year study period. They demonstrated that women with fewer children exhibited shorter TLs than those who had more children. In the same study, Barha et al found that estradiol, the levels of which increase during pregnancy and is a potent antioxidant, protects TL (43). Czamanski-Cohen et al measured TL in lymphocytes of peripheral blood in women undergoing in vitro fertilization (IVF) techniques due to infertility; women undergoing IVF were found to have statistically significant shorter telomeres compared to the healthy controls in various phases of the menstrual cycle (44). In addition, lifestyle factors, such as employment and the work schedule are related to TL in women (45). Moreover, estradiol increases TA, maintains TL, and has been related to pregnancy complications (46).

However, a late maternal age was reported in centenarians, supporting that a maternal age over 33 years is a marker of slow aging, predicting a longer life expectancy $(47,48)$. Fagan et al and others have shown that the genetic basis between reproductive age, longevity and biological aging is strongly associated with TL $(49,50)$.

In a nationally representative, cross-sectional study which included 1,954 women of reproductive age from the National Health and Nutrition Examination Survey, leukocyte
TL (LTL) was measured by polymerase chain reaction (PCR). It was found that the women who had at least one live birth versus those that had biochemical pregnancies, spontaneous abortions, still births, or other pregnancy complications, had a shorter TL associated with accelerated cellular aging. The early decline observed in the reproductive potential of women was suggested to be associated with TL, which declines earlier in the reproductive system than it does in somatic cells (40).

According to Hapangama et al, endometrial telomerase exhibits specific expression patterns in various types of reproductive failure. Their study included endometrial biopsies during the window of implantation from women with idiopathic recurrent loss of empty gestational sacs, fetal loss after cardiac activity identification and recurrent implantation failure. No significant differences were observed in the mean TL between the groups. However, telomerase immunostaining was found to be elevated in endometrial samples from women with reproductive failure of all types, particularly those with recurrent implantation failure (51).

Additionally, Butts et al and others have revealed a short granulosa cell TL (GTL) and lower telomere DNA in patients with occult ovarian insufficiency (OOI) $(52,53)$. Premature ovarian insufficiency (POI) has also been linked to both a shorter LTL and GTL (54). A short TL has been found in tubal epithelial cells in a study that supported the proposal that serous tubal intraepithelial carcinomas (STICs) are precursors of high-grade serous carcinoma (HGSC), potentially an early event in ovarian high-grade serous carcinogenesis (55). Another factor commonly leading to infertility is polycystic ovary syndrome (PCOS). Several studies have focused on the association between TL and PCOS. However, studies differ in the type of association and correlation. Of the 7 studies reviewed, 3 studies showed a negative association between LTL and PCOS patients (35-37) while Wei et al demonstrated significantly longer GTL but a negative association between LTL and PCOS patients (56). Further, 1 study revealed significantly longer LTL in patients with PCOS (57). Contrastingly, Li et al demonstrated that LTL was shorter in women with PCOS and that a short LTL increased the risk of disease (58). A different group demonstrated shorter GTL and an earlier onset of infertility symptoms in women with lower TA levels and PCOS (59).

In addition, a longer TL is widely observed in women with endometriosis. The tissue-specific regulation of TL in patients with endometriosis has been suggested, as endometrial TL is significantly longer, but not is not associated with LTL, which correlates with circulating estradiol levels $(33,60)$. Additionally, endometrial TL has been shown to exhibit a positive correlation with the glandular and stromal expression of nucleolin, involved in the exponential growth of eukaryotic cells (35). A high telomerase activity was seen in the secretory phase of infertile women with endometriosis when compared to healthy women or fertile women with endometriosis (61). Similarly, significantly higher expression of telomerase activity, longer mean TLs, lower expression of genes for steroid receptors was found in ectopic endometriosis lesions (62). Furthermore, Hanna et al demonstrated a long LTL in women with premature ovarian failure (POF) (63). Lastly, telomere lengths are varied with specific histologic types in ovarian carcinomas. Specifically, short TLs are observed in tubal epithelial cells of serus tubal 


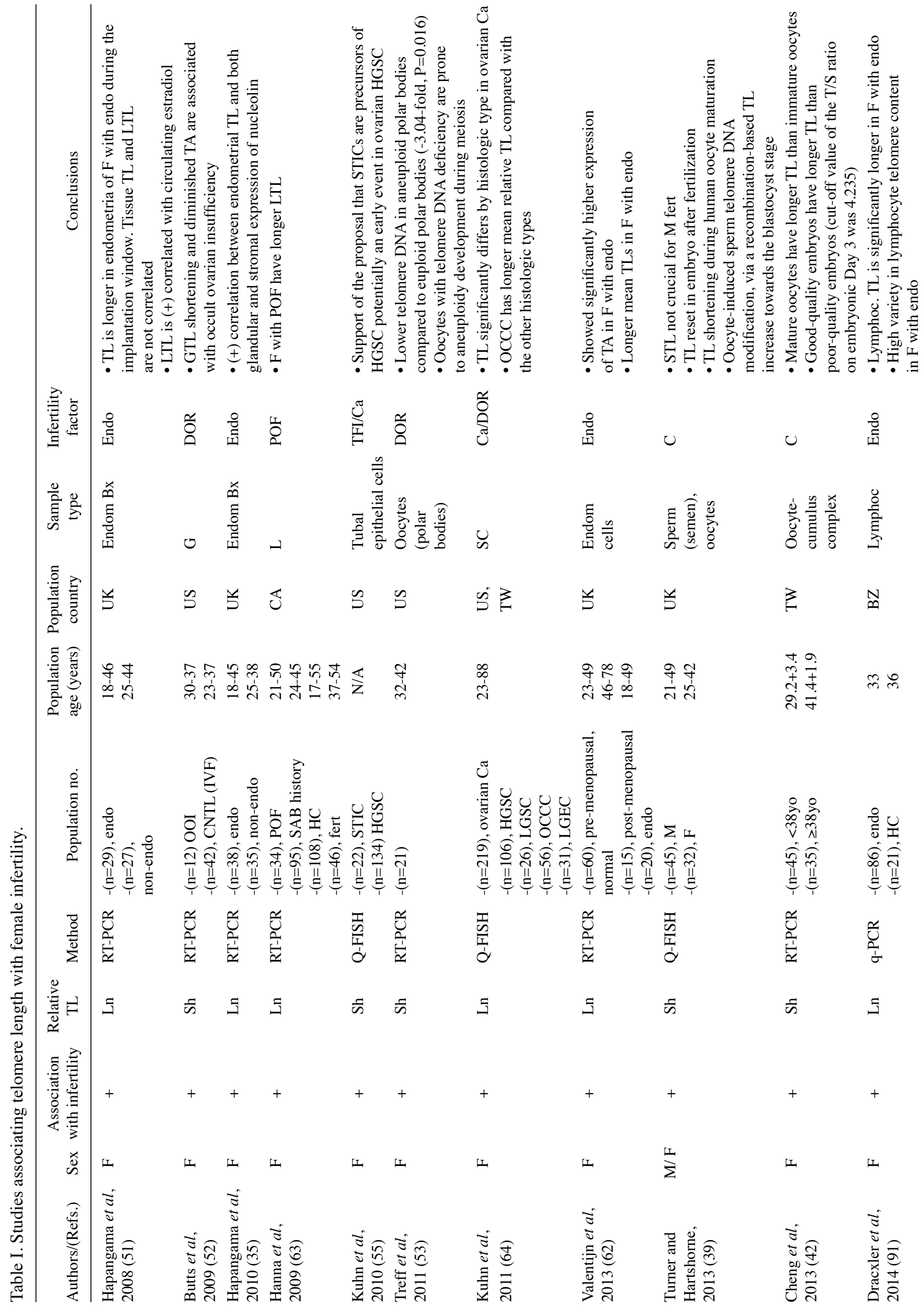




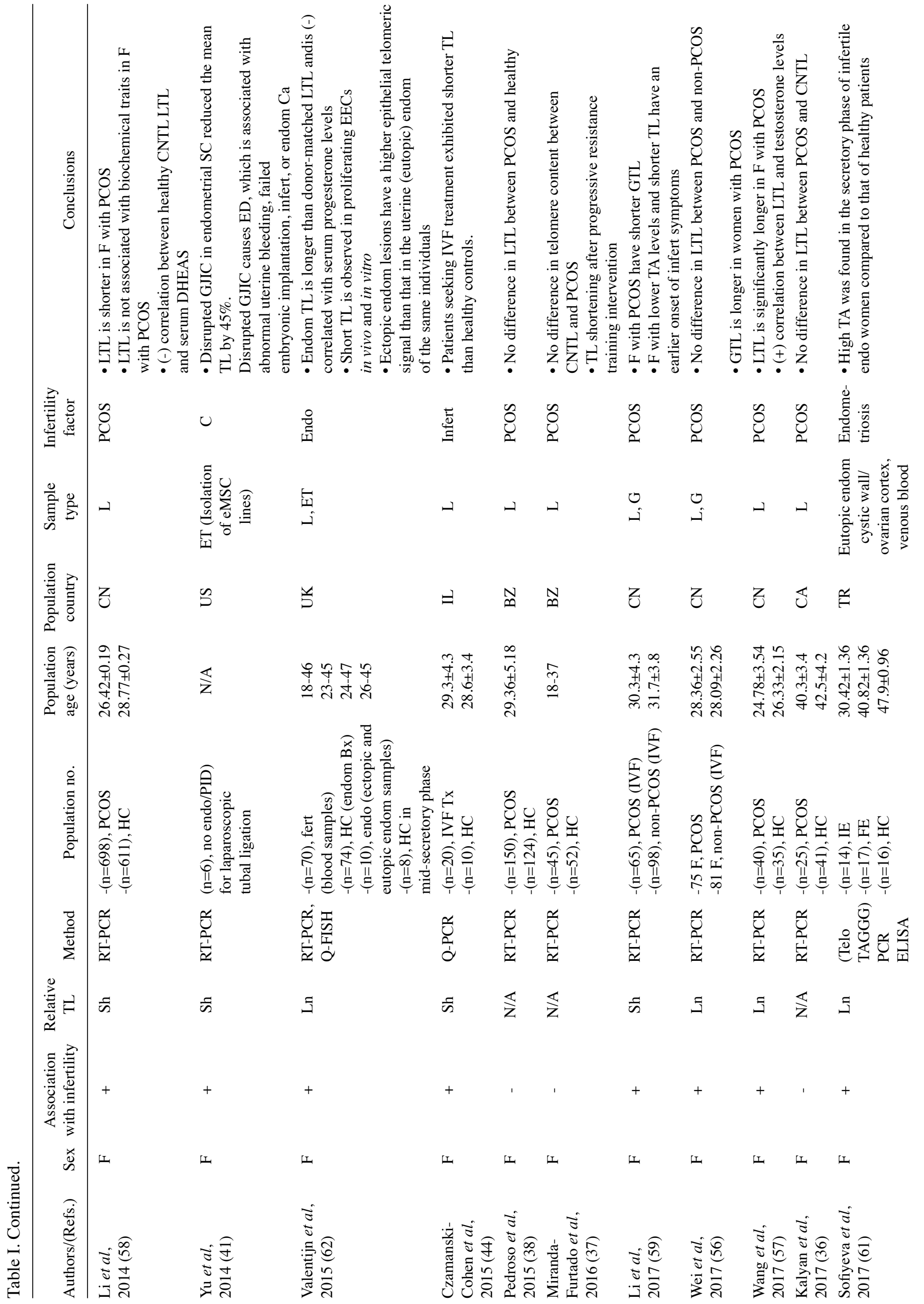




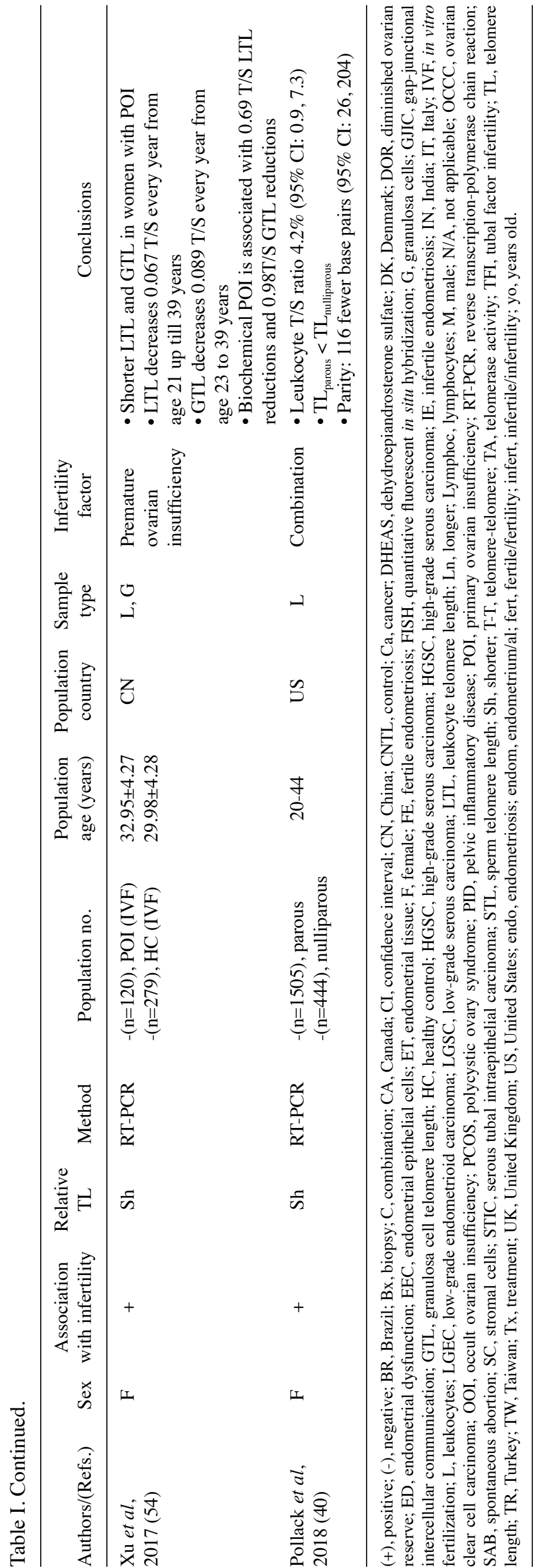

intraepithelial carcinoma (STIC), an early event in ovarian high-grade serous carcinogenesis (55). However, stromal cells of clear cell carcinoma have longer mean relative TL compared to other histologic types (64). An overview of the link between TL, fertility and lifespan in women is presented in Fig. 3.

The female reproductive system poses certain paradoxes. Although somatic tissues of the uterus remain well-functioning and receptive throughout the reproductive years, oocytes exhibit precocious profound aging. Meiotic dysfunction increasingly afflicts women as they age, resulting in infertility, miscarriage, and offspring with congenital abnormalities (65). For normal reproduction, the biological state of the ovum is of high importance. Apart from TL in lymphocytes, another factor that appears to be associated with fertility is the TL of oocytes.

According to the study by Kalmbach et al, reproductive aging involves declines in both oocyte number and developmental capacity. In women, the effects of reproductive aging on oocyte quality are largely explained by telomere shortening (66). Also paradoxical, is that despite the reduction of telomeres with aging, their length resets across generations via the novel mechanism involving recombination and sister chromatid exchange in the early cell cycles, and with telomerase activity after the blastocyst stage (67).

\section{Telomere length and male infertility}

A positive association between male infertility factors and TL was observed in 19 studies (68-86) and a negative association in 2 studies $(39,87)$ (Table II). In total, 15 of the positively associated studies detected a sperm TL (STL) association (68-70,72,74-84), while 3 studies detected an LTL association $(73,85,86)$, and one study detected both STL and LTL (71). In several studies, shorter STL was reported in association to infertility $(72,76,78,80)$ while Vecoli et al reported an increase in STL in areas of high environmental exposure (77). Although Turner and Hartshorne found an association between female fertility and STL, they did not find a significant association for male fertility (39). Further, a study focusing on paternal age at the time of conception reported no significant change in TL between younger and older males (87). On the other hand, paternal age at birth has been shown to be positively correlated with LTL (73) and with offspring LTL in the nurses' health study (8). An overview of the link between TL, and fertility in men is presented in Fig. 4.

Antunes et al reported a longer and more variable STL with an older age (83), and Mishra et al reported the disruption of normal telomere interactions, leading to the loss of the looped chromosomal configuration (80). In the latter study on 112 infertile men, seminal ROS and 8-isoprostane levels were reported to be increased compared to the controls, demonstrating that the infertile men experienced some form of oxidative stress. When TL was measured using reverse transcription-polymerase chain reaction (RT-PCR) and correlated with reactive oxygen species (ROS) levels, it was suggested that mild oxidative stress caused the lengthening of telomeres, whereas in severe oxidative stress, TL was shorter in comparison to TL when normal ROS levels. Therefore, mild oxidative stress and the progression of meiosis in infertile men is beneficial to TL as it correlates with their increased lengths, whereas severe oxidative stress has harmful effects (80). In a previous study, in sperm samples 


\section{TELOMERES}

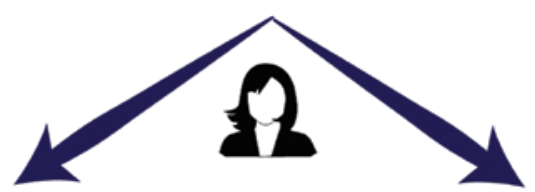

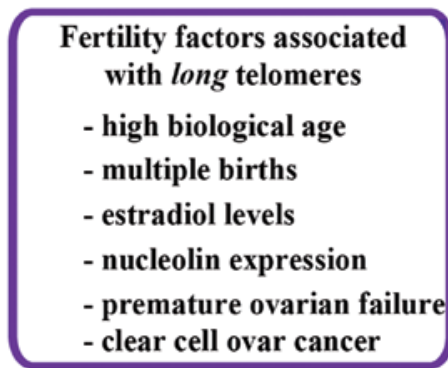

Fertility deprovement associated with short telomeres - post-menopausal women who attained parity

- recurrent miscarriage

- ovarian insufficiency

- oocyte maturation

- telomere length decrease from 21 to 39 years

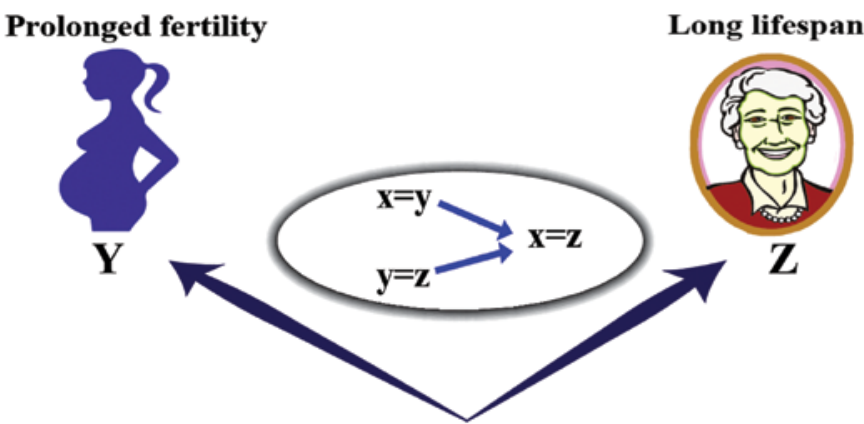

Long telomere

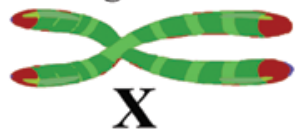

The link between long telomeres, fertility and age in women

Figure 3. Telomere length is associated with aging and several infertility factors in females. Analysis of the present literature showed certain fertility/infertility characteristics and factors are associated with long TL and others are associated with short TL. Additionally, long TL has shown to lead to prolonged fertility which in turn leads to a long lifespan. Therefore, long telomeres can lead to a longer lifespan.

with high DNA damage based on the DNA fragmentation index (DFI) that underwent fluorescence in situ hybridization analysis (FISH) there was an increased number of telomere signals compared to those with a low DFI. This could be due to abnormal telomere-telomere interactions in the case of DNA damage, evident by the fact that in low DFI, almost $71 \%$ of the samples had normal telomere distribution, whereas in high DFI, this number dropped to $42 \%$ (74).

A high expression of telomerase has been reported in undifferentiated spermatogonia and the complete depletion of telomerase produces telomere shortening and the eventual loss of germ line cells, since undifferentiated spermatogonia reduce significantly (88). It has also been shown that telomerase association at telomeres is reduced in testes cells of patients with idiopathic infertility. Telomere repeat-containing RNA (TERRA) was also found to be reduced in the same study, although TL was not affected. However, the study pointed out that telomere integrity is thought to be affected with aberrant telomerase association, leading to reduced fertility (69).

Additionally, men with oligospermia have been found to have a shorter STL and a positive correlation has been found between a shorter STL and total sperm count $(68,71,79)$, LTL and paternal age (71), and a positive correlation between a shorter STL and sperm diploidy has also been found (79). Moreover, samples that were used for IVF and had abnormal STLs did not produce a successful pregnancy, whereas samples that had STLs within the normal range had a 35.7\% success rate (79). Likewise, males with azoospermia exhibited a shortened STL $(69,70)$, as well as a shorter LTL $(85,86)$.

Baird et al performed terminal restricted fragment (TRF) length and single TL (STELA) analysis in 54 human semen samples. The results from STELA on XpYp coincided with results from the TRF analysis and revealed that only 19\% of germ cells would at any time have a full set of chromosomes with genome-wide TL and would not be truncated. Truncated telomeres may result in abnormal synapsis during meiotic cell division or in aneuploids observed in human sperm which may explain the miscarriages and abortions observed in couples trying to have a baby and the reduced fecundity of humans (75). Previous studies have shown that men with genotypes containing 2 specific genetic variants of telomerase reverse transcriptase (TERT) and telomerase-associated protein 1 (TEP1) have the chance of being infertile increased by $100 \%$. In particular, TERT rs 2736100 is negatively associated with male infertility risk, whereas TEP1 rs1713449 is positively associated with male infertility. Individuals with 


\section{TELOMERES}

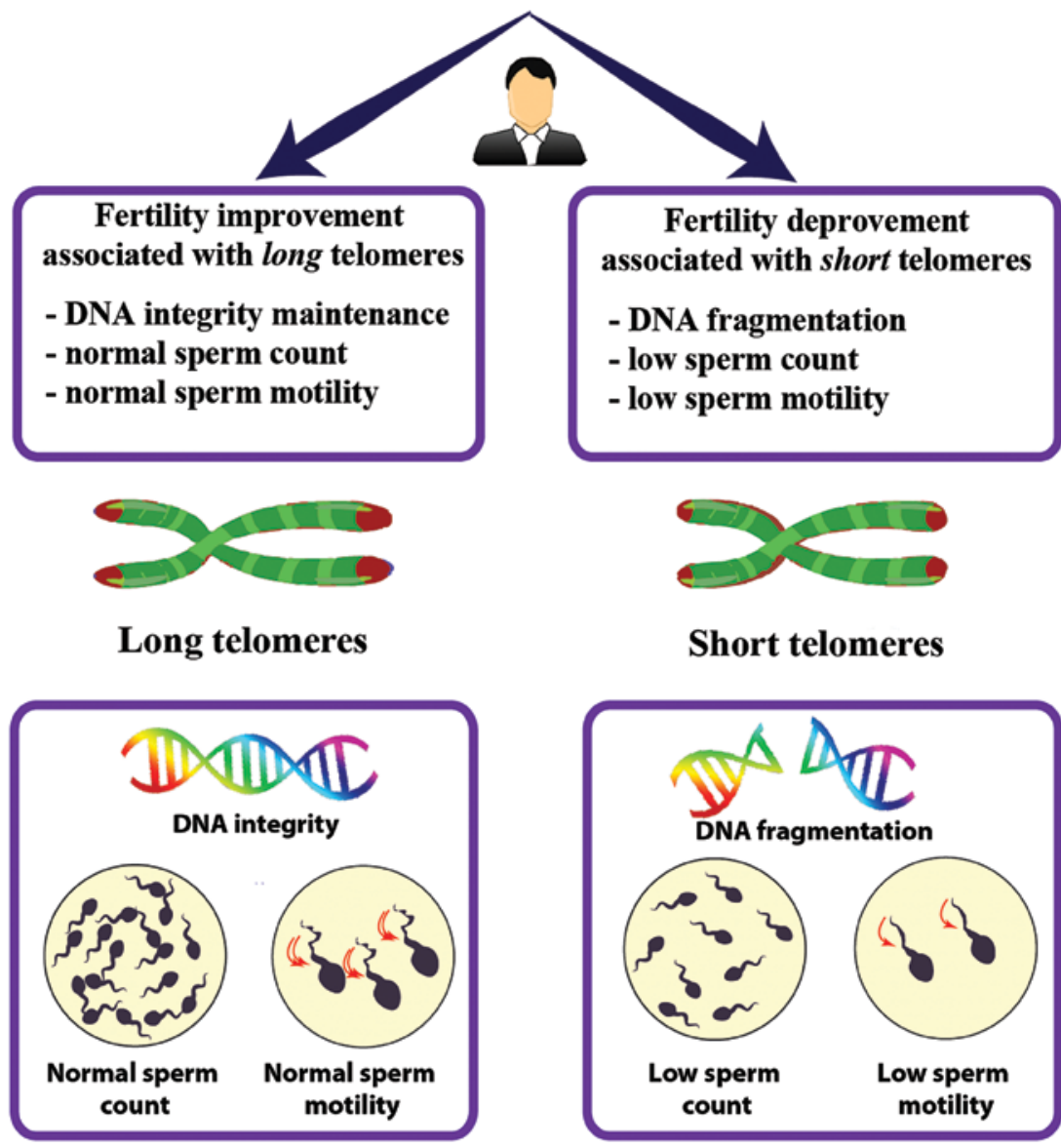

\section{The link between long and short telomeres and fertility in men}

Figure 4. Telomere length is associated with infertility factors in males. Long telomeres are linked to characteristics associated with increased fertility in males, such as DNA integrity, normal sperm count/motility. Short telomeres are linked to characteristics such as DNA fragmentation, and low sperm count/ motility, and other male infertility factors.

the TEP1 rs1713449 variant also exhibit an increased DFI. Therefore, these genetic variations play a role in the risk of male infertility (70).

In patients with decreased sperm motility, a shorter STL has been found and has also been associated with a lower sperm count, vitality and protamination $(81,82)$, but negatively associated with DNA fragmentation in normozoospermic individuals (81). Abnormal semen quality, according to the WHO criteria, has been associated with a shorter TL than that of semen with normal parameters. Lastly, men with idiopathic male infertility have been shown to have a short STL (72).

STL is significantly affected by environmental factors, such as pollution. In a study carried out in Southern Italy, it was found that STL was higher in individuals that resided in a highly polluted area (77). The effect of polycyclic aromatic hydrocarbons (PAHs) on STL was assessed in a large study with 666 participants. The results revealed that a high concentration of urinary PAH metabolites was associated with shorter STLs. However, semen quality or sperm apoptosis did not appear to be influenced by PAHs. Moreover, benzo $(\alpha)$ pyrene administration also caused the shortening of STL and reduced telomerase expression in the germline in a dose-dependent manner (89). Anticancer agents have also been investigated for their effects on TL. Of the 4 agents tested, 2 alkylating agents, cisplatin and 4-hydroperoxycyclophosphamide resulted in a shorter TL, a reduced TA, reduced telomere specific fluorescence in FISH experiments, and the mRNA expression of two components of the telomerase. All of the above can lead to reduced fertility and developmental issues in offspring (90).

Another study demonstrated that aberrant fertilization and embryo cleavage were the result of fertilization with either one or both of the gametes being telomerase deficient. In these telomerase-null gametes, a small subset of telomeres was not present in some metaphase I chromosomes, suggesting that the absence of telomerase causes telomere shortening and eventually loss (84). In cases of idiopathic recurrent pregnancy loss, LTL was measured in suffering couples and compared to the controls. A statistically significantly shorter LTL was found in both males and females of the suffering couples in addition to the present TL decrease observed in males due to age. A positive correlation between the LTL and sperm DNA fragmentation index was also found, but it was not statistically significant (72).

Collectively, a prominent trend can be observed towards a shorter TL in both sperm and leukocytes, associated with the male factor in infertility. An overview of the link between TL and fertility in males is presented in Fig. 4. 


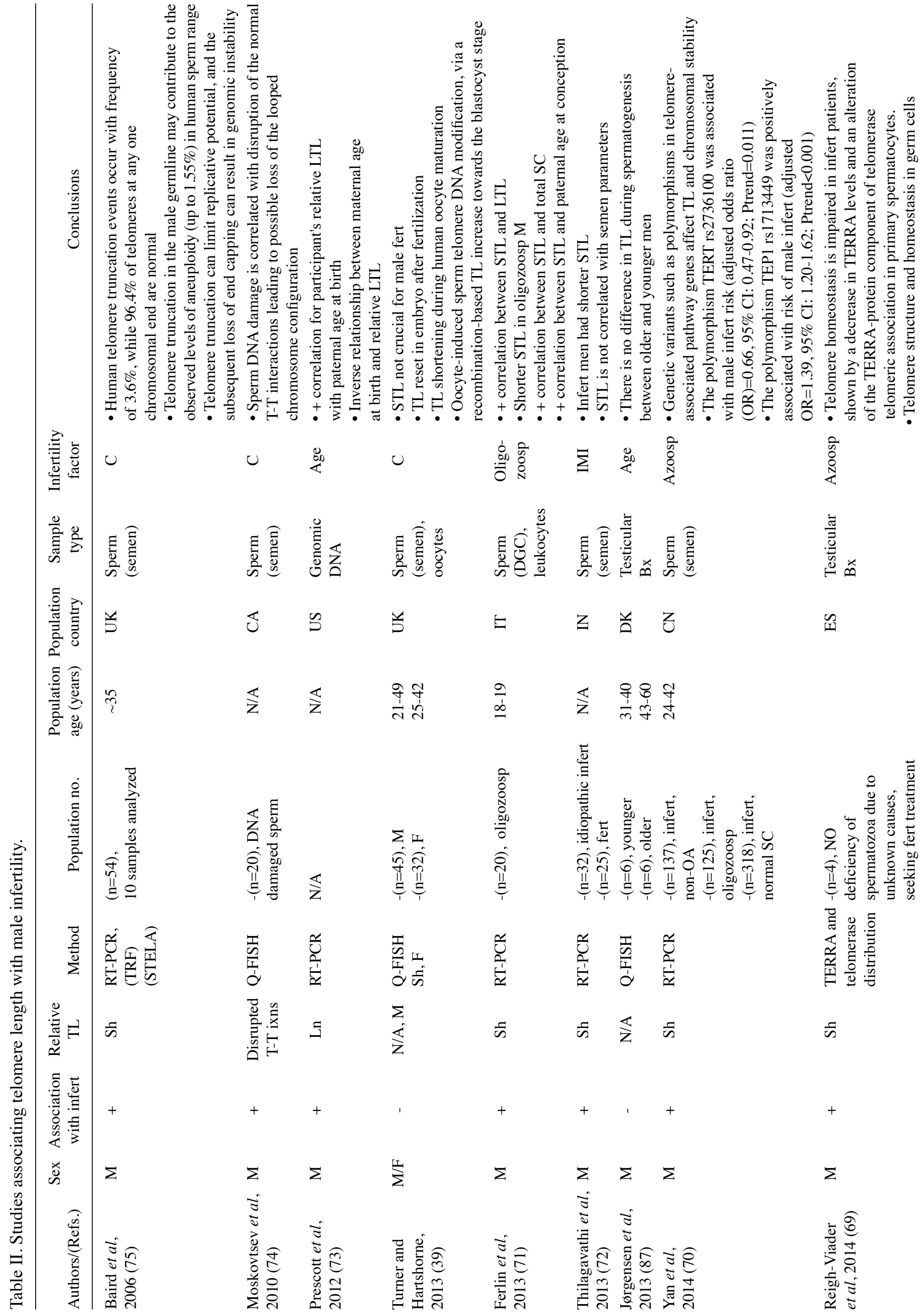




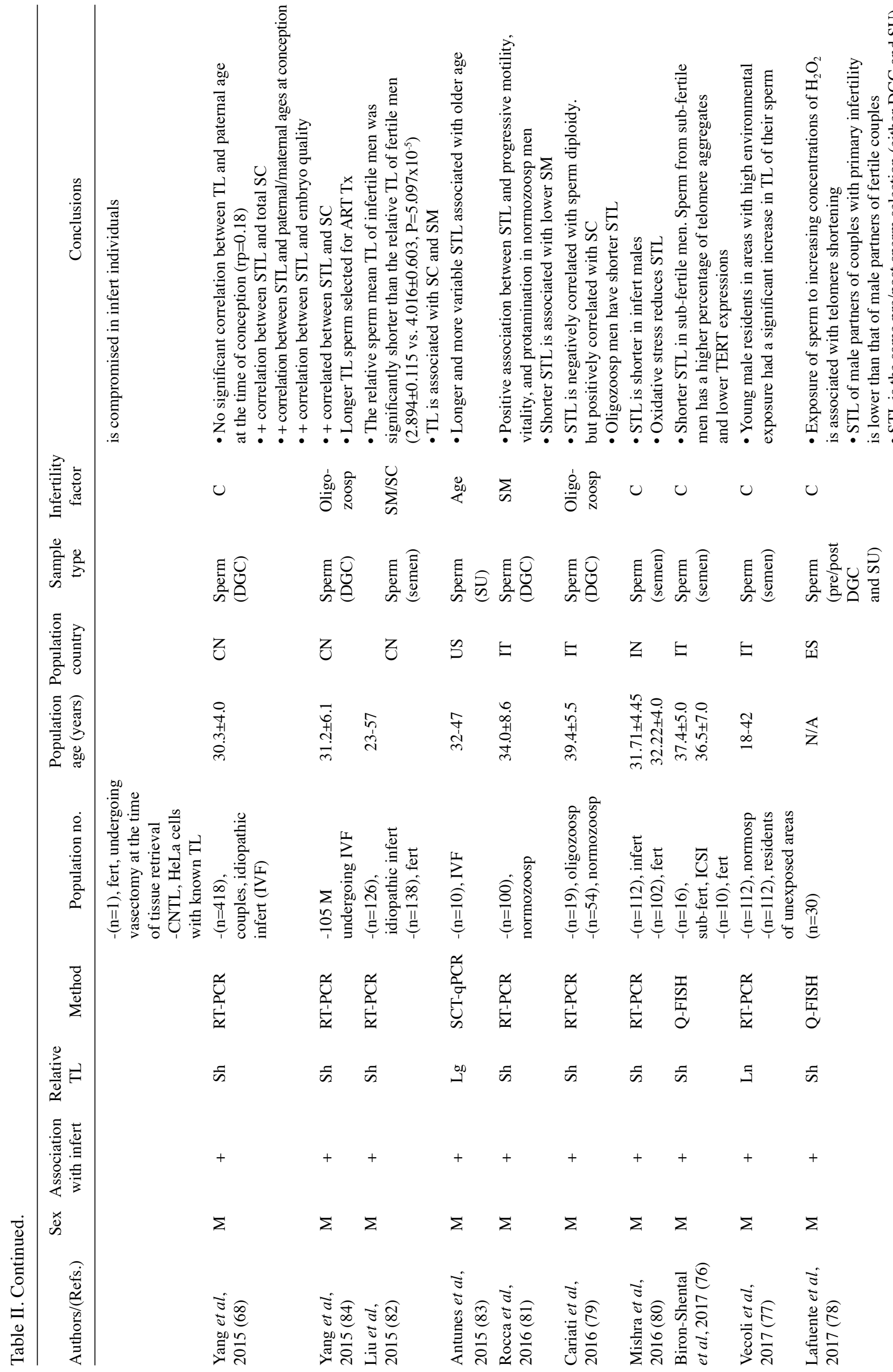




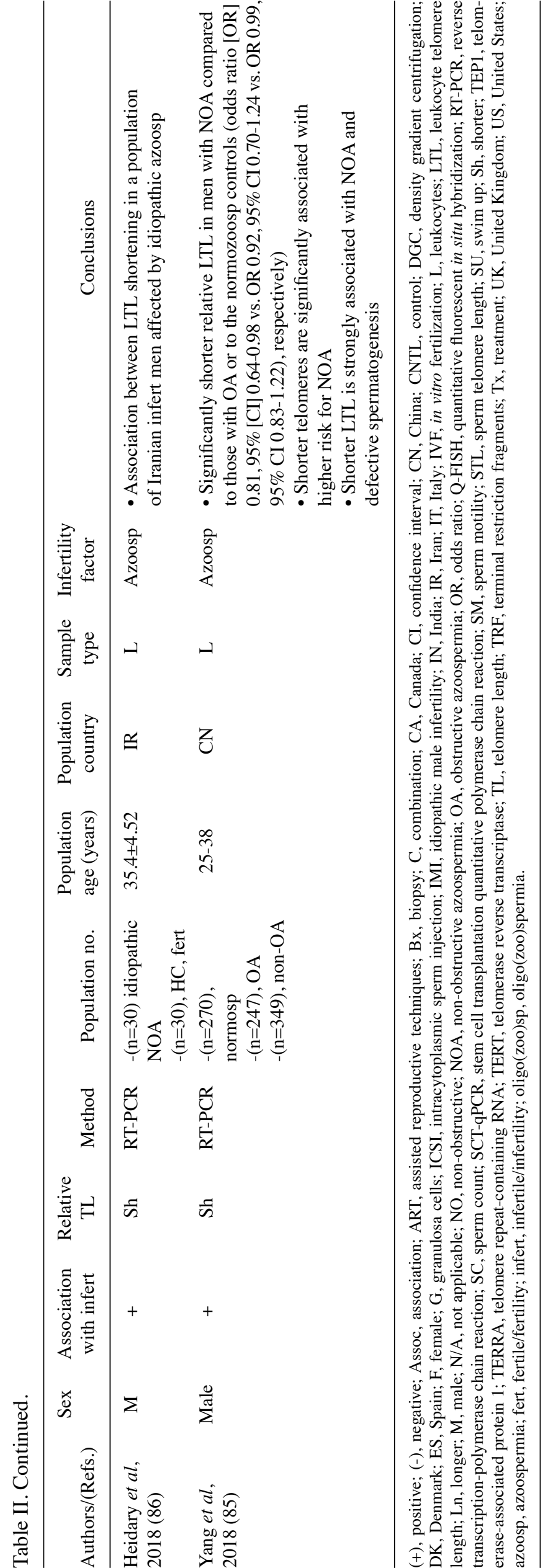

\section{Conclusions and future perspectives}

In light of the increasing life expectancies of individuals worldwide, age-related diseases, such as infertility have progressively become a greater medical and social concern. The standard laboratory markers for age-related diseases or infertility have been insufficient. TL has long been a marker of cellular aging. The question posed is whether TL can be used to predict not only the biological, but also the reproductive age. Multiple studies have focused on elucidating this question and have demonstrated that infertility is in fact most often associated with shorter telomeres. Specifically, a trend associating female infertility factors, such as PCOS, DOR, ovarian insufficiency and tubal factor with shorter TLs was observed in oocyte granulosa cells, endometrial tissue and leukocytes. On the contrary, longer TLs were observed in endometrial biopsy, the eutopic endometrium, cyst and lymphocyte tissue in cases of endometriosis. As regards studies focusing on male infertility factors, including azoospermia, oligospermia, abnormal sperm motility and idiopathic male infertility, these demonstrated a shorter TL in either sperm or leukocyte samples obtained.

Although this study was able to identify major trends in the association of several factors of infertility and TL, limitations apply due to the relatively low number of relevant studies for each infertility factor published to date. Additionally, TL in a number of established factors of infertility has not yet been studied. Specifically, no published literature on oligospermia, hypospermia, teratosperimia, aspermia, asthenozospermia, necrozospermia, leukospermia and hydrosalpinx was found. Although this serves as a limitation, it indicates a knowledge gap where further research could be undertaken. Regardless, TL is associated with a sufficient amount of infertility factors, thus not compromising the external validity of the review.

As regards female infertility factors, ovarian HGSC, mature oocytes, low-quality embryos, multiform endometrial dysfunction, premature ovarian insufficiency, DOR, and nulliparity were all linked to a shorter TL. Conversely, all studies on endometriosis and TL agreed that TLs are longer. Additionally, one study noted that clear cell carcinoma stromal cells exhibit longer TL that other histological types. A noticeable disagreement is evident in studies exploring the TL of females with PCOS, as TL has been negatively and positively associated, and further correlated to both a shorter and longer TL in different studies. Thus, although for all other above-mentioned infertility factors a clear conclusion is drawn, for PCOS, the present evidence is inconclusive. Of the 21 studies reviewed focusing on male infertility factors, 1 study showed no association between TL in the sperm of older versus younger males, while 2 studies showed that older males had a longer relative TL and one study found STL not crucial for male fertility. Furthermore, the remaining studies were in agreement, indicating a shorter TL in infertile patients.

With recent advances in reproductive technology, we need powerful predictive biomarkers that will improve the clinical strategy in individuals with infertility. TL can be a marker used to identify the reproductive capacity. Additionally, premature senescence can be avoided by the use of drugs 
preventing telomere shortening, thereby increasing the reproductive capacity of patients. However, many questions must first be answered before the efficient use of such methods in a clinical setting is possible. It is critical that further studies are conducted to understand the bases of TL associations with biological aging and reproductive capacity.

The strength of this review is that, at least to the best of our knowledge, this is the first collection of the results from human epidemiological studies exploring the association of different factors of infertility and TL. Despite the present limitations, this review may be a useful aid, and the studies mentioned, may function as building blocks for further research needed to establish further associations and to determine how this knowledge can be used in medical applications.

\section{Acknowledgements}

Not applicable.

\section{Funding}

This study was funded by Metabolomic Medicine S.A. and Spin-Off Toxplus S.A. and supported by the Special Research Account of University of Crete (ELKE nos. 4602, 4920 and 3963).

\section{Availability of data and materials}

Not applicable.

\section{Authors' contributions}

All the authors (EVasilopoulos, PF, CK, DF, AOD, EVakonaki, DT, DC, AMP, GG, CM, AM, DAS and AT) contributed to conceiving and designing the study. EVasilopoulos and CK searched the literature for inclusion in the study that was then checked and reviewed by AOD, EV, DT, DC, AMB, GG and CM. EVasilopoulos, PF, CK, DF, AOD, EV, DT, DC, AMB and GG drafted and wrote the manuscript. AM, DAS, AT, CM provided advice on the experimental design, interpreted the results and critically revised the manuscript. AOD, DC, AMB, DT, EV, GG designed the figures. CK and EV designed the tables. All authors have read and approved the final version of the manuscript.

\section{Ethics approval and consent to participate}

Not applicable.

\section{Patient consent for publication}

Not applicable.

\section{Competing interests}

DAS is the Editor-in-Chief for the journal, but had no personal involvement in the reviewing process, or any influence in terms of adjudicating on the final decision, for this article. The other authors declare that they have no competing interests.

\section{References}

1. Aghajanova L, Hoffman J, Mok-Lin E and Herndon CN: Obstetrics and gynecology residency and fertility needs. Reprod Sci 24: 428-434, 2017.

2. Center for Disease Control and Prevention: Assisted reproductive technology success rates: National summary and fertility clinic reports, 2016. www.cdc.gov/art/pdf/2016-report/ART-2016National-Summary-Report.pdf.

3. Society for Assisted Reproductive Technology: National Summary Report. Society for Assisted Reproductive Technology, 2016. www.sartcorsonline.com/rptCSR_PublicMultYear.aspx? reportingYear $=2016$.

4. Agarwal A, Mulgund A, Hamada A and Chyatte MR: A unique view on male infertility around the globe. Reprod Biol Endocrinol 13: 37, 2015

5. Artini PG, Obino ME, Vergine F, Sergiampietri C, Papini F and Cela V: Assisted reproductive technique in women of advanced fertility age. Minerva Ginecol 70: 738-749, 2018.

6. Zhang WG, Zhu SY, Bai XJ, Zhao DL, Jian SM, Li J, Li ZX, $\mathrm{Fu}$ B, Cai GY, Sun XF, et al: Select aging biomarkers based on telomere length and chronological age to build a biological age equation. Age (Dordr) 36: 9639, 2014.

7. Pfeiffer V and Lingner J: Replication of telomeres and the regulation of telomerase. Cold Spring Harb Perspect Biol 5: a010405, 2013.

8. Jones MJ, Goodman SJ and Kobor MS: DNA methylation and healthy human aging. Aging Cell 14: 924-932, 2015.

9. Rizvi S, Raza ST and Mahdi F: Telomere length variations in aging and age-related diseases. Curr Aging Sci 7: 161-167, 2014.

10. Tsatsakis A, Tsoukalas D, Fragkiadaki P, Vakonaki E, Tzatzarakis M, Sarandi E, Nikitovic D, Tsilimidos G and Alegakis AK: Developing BIOTEL: A semi-automated spreadsheet for estimating telomere length and biological age. Front Genet 10: 84, 2019.

11. Petrakis D, Vassilopoulou L, Mamoulakis C, Psycharakis C, Anifantaki A, Sifakis S, Docea AO, Tsiaoussis J, Makrigiannakis A and Tsatsakis AM: Endocrine disruptors leading to obesity and related diseases. Int J Environ Res Public Health 14: E1282, 2017.

12. Mehrpour O, Karrari P, Zamani N, Tsatsakis AM and Abdollahi M: Occupational exposure to pesticides and consequences on male semen and fertility: A review. Toxicol Lett 230: 146-156, 2014

13. Kalliora C, Mamoulakis C, Vasilopoulos E, Stamatiades GA, Kalafati L, Barouni R, Karakousi T, Abdollahi M and Tsatsakis A: Association of pesticide exposure with human congenital abnormalities. Toxicol Appl Pharmacol 346: 58-75, 2018.

14. Sifakis S, Androutsopoulos VP, Tsatsakis AM and Spandidos DA: Human exposure to endocrine disrupting chemicals: Effects on the male and female reproductive systems. Environ Toxicol Pharmacol 51: 56-70, 2017.

15. Katsikantami I, Sifakis S, Tzatzarakis MN, Vakonaki E, Kalantzi OI, Tsatsakis AM and Rizos AK: A global assessment of phthalates burden and related links to health effects. Environ Int 97: 212-236, 2016.

16. Yawson Emmanuel O, Obasi KK and Lawal I: Spermatogenic and spermatotoxic effects of Telfairia occidentalis (Ugu) aqueous leaves extract in adult male Wistar rats (Rattus novergicus). Toxicol Rep 5: 954-958, 2018.

17. Acosta IB, Junior ASV, E Silva EF, Cardoso TF, Caldas JS, Jardim RD and Corcini CD: Effects of exposure to cadmium in sperm cells of zebrafish, Danio rerio. Toxicol Rep 3: 696-700, 2016.

18. Mello MSC, Delgado IF, Favareto APA, Lopes CMT, Batista MM, Kempinas WD and Paumgartten FJR: Sexual maturation and fertility of mice exposed to triphenyltin during prepubertal and pubertal periods. Toxicol Rep 2: 405-414, 2014.

19. Vakonaki E, Tzatzarakis M, Tsiminikaki K, Nathena D, Fragkiadaki P, Kalliantasi K, Kanaki K, Vaki G, Plaitis S, Tsoukalas D, et al: Effect of chronic and heavy drug abuse on biological aging. World Acad J Sci 1: 67-73, 2019.

20. Tsoukalas D, Fragkiadaki P, Docea AO, Alegakis AK, Sarandi E, Vakonaki E, Salataj E, Kouvidi E, Nikitovic D, Kovatsi L, et al: Association of nutraceutical supplements with longer telomere length. Int J Mol Med 44: 218-226, 2019.

21. Shammas MA: Telomeres, lifestyle, cancer, and aging. Curr Opin Clin Nutr Metab Care 14: 28-34, 2011.

22. Valassi E, Crespo I, Santos A and Webb SM: Clinical consequences of Cushing's syndrome. Pituitary 15: 319-329, 2012. 
23. Tedone E, Huang E, O'Hara R, Batten K, Ludlow AT, Lai TP Arosio B, Mari D, Wright WE and Shay JW: Telomere length and telomerase activity in T cells are biomarkers of high-performing centenarians. Aging Cell 18: e12859, 2019.

24. Kordinas V, Ioannidis A and Chatzipanagiotou S: The telomere/ telomerase system in chronic inflammatory Diseases. Cause or effect? Genes (Basel) 7: E60, 2016.

25. Chakravarthi BV, Nepal S and Varambally S: Genomic and epigenomic alterations in cancer. Am J Pathol 186: 1724-1735, 2016.

26. Moher D, Liberati A, Tetzlaff J, Altman DG and Group P; PRISMA Group: Preferred reporting items for systematic reviews and meta-analyses: The PRISMA statement. PLoS Med 6 : e1000097, 2009

27. Ma H, Zhou Z, Wei S, Liu Z, Pooley KA, Dunning AM Svenson U, Roos G, Hosgood HD III, Shen M, et al: Shortened telomere length is associated with increased risk of cancer: A meta-analysis. PLoS One 6: e20466, 2011.

28. Haycock PC, Heydon EE, Kaptoge S, Butterworth AS Thompson A and Willeit P: Leucocyte telomere length and risk of cardiovascular disease: Systematic review and meta-analysis. BMJ 349: g4227, 2014.

29. Willeit P, Raschenberger J, Heydon EE, Tsimikas S, Haun M, Mayr A, Weger S, Witztum JL, Butterworth AS, Willeit J, et al: Leucocyte telomere length and risk of type 2 diabetes mellitus: New prospective cohort study and literature-based meta-analysis. PLoS One 9: e112483, 2014.

30. Aviv A, Kark JD and Susser E: Telomeres, atherosclerosis, and human longevity: A causal hypothesis. Epidemiology 26: 295-299, 2015.

31. Zhang J, Rane G, Dai X, Shanmugam MK, Arfuso F, Samy RP, Lai MK, Kappei D, Kumar AP and Sethi G: Ageing and the telomere connection: An intimate relationship with inflammation. Ageing Res Rev 25: 55-69, 2016.

32. Parks CG, DeRoo LA, Miller DB, McCanlies EC, Cawthon RM and Sandler DP: Employment and work schedule are related to telomere length in women. Occup Environ Med 68: 582-589, 2011.

33. Valentijn AJ, Saretzki G, Tempest N, Critchley HO and Hapangama DK: Human endometrial epithelial telomerase is important for epithelial proliferation and glandular formation with potential implications in endometriosis. Hum Reprod 30 2816-2828, 2015.

34. Williams CD, Boggess JF, LaMarque LR, Meyer WR, Murray MJ, Fritz MA and Lessey BA: A prospective, randomized study of endometrial telomerase during the menstrual cycle. J Clin Endocrinol Metab 86: 3912-3917, 2001.

35. Hapangama DK, Turner MA, Drury J, Heathcote L, Afshar Y, Mavrogianis PA and Fazleabas AT: Aberrant expression of regulators of cell-fate found in eutopic endometrium is found in matched ectopic endometrium among women and in a baboon model of endometriosis. Hum Reprod 25: 2840-2850, 2010

36. Kalyan S, Patel MS, Kingwell E, Côté HCF, Liu D and Prior JC: Competing factors link to bone health in polycystic ovary syndrome: Chronic low-grade inflammation takes a toll. Sci Rep 7: 3432, 2017.

37. Miranda-FurtadoCL, Ramos FK, Kogure GS, Santana-Lemos BA, Ferriani RA, Calado RT and Dos Reis RM: A nonrandomized trial of progressive resistance training intervention in women with polycystic ovary syndrome and its implications in telomere content. Reprod Sci 23: 644-654, 2016.

38. Pedroso DC, Miranda-Furtado CL, Kogure GS, Meola J, Okuka M, Silva C, Calado RT, Ferriani RA, Keefe DL and dos Reis RM: Inflammatory biomarkers and telomere length in women with polycystic ovary syndrome. Fertil Steril 103: 542-547.e2, 2015.

39. Turner S and Hartshorne GM: Telomere lengths in human pronuclei, oocytes and spermatozoa. Mol Hum Reprod 19: 510-518, 2013

40. Pollack AZ, Rivers K and Ahrens KA: Parity associated with telomere length among US reproductive age women. Hum Reprod 33: 736-744, 2018.

41. Yu J, Berga SL, Zou W, Sun HY, Johnston-MacAnanny E, Yalcinkaya T, Sidell N, Bagchi IC, Bagchi MK and Taylor RN Gap junction blockade induces apoptosis in human endometrial stromal cells. Mol Reprod Dev 81: 666-675, 2014.

42. Cheng EH, Chen SU, Lee TH, Pai YP, Huang LS, Huang CC and Lee MS: Evaluation of telomere length in cumulus cells as a potential biomarker of oocyte and embryo quality. Hum Reprod 28: 929-936, 2013.
43. Barha CK, Hanna CW, Salvante KG, Wilson SL, Robinson WP, Altman RM and Nepomnaschy PA: Number of children and telomere length in women: A prospective, longitudinal evaluation. PLoS One 11: e0146424, 2016.

44. Czamanski-Cohen J, Sarid O, Cwikel J, Douvdevani A, Levitas E, Lunenfeld E and Har-Vardi I: Cell-free DNA and telomere length among women undergoing in vitro fertilization treatment. J Assist Reprod Genet 32: 1697-1703, 2015.

45. Shalev I, Entringer S, Wadhwa PD, Wolkowitz OM, Puterman E, Lin J and Epel ES: Stress and telomere biology: A lifespan perspective. Psychoneuroendocrinology 38: 1835-1842, 2013.

46. Fragkiadaki P, Tsoukalas D, Fragkiadoulaki I, Psycharakis C, Nikitovic D, Spandidos DA and Tsatsakis AM: Telomerase activity in pregnancy complications (Review). Mol Med Rep 14: 16-21, 2016.

47. Perls TT, Alpert L and Fretts RC: Middle-aged mothers live longer. Nature 389: 133, 1997.

48. Sun F, Sebastiani P, Schupf N, Bae H, Andersen SL, McIntosh A, Abel H, Elo IT and Perls TT: Extended maternal age at birth of last child and women's longevity in the Long Life Family Study. Menopause 22: 26-31, 2015

49. Fagan E, Sun F, Bae H, Elo I, Andersen SL, Lee J, Christensen K, Thyagarajan B, Sebastiani P, Perls T, et al; Long Life Family Study: Telomere length is longer in women with late maternal age. Menopause 24: 497-501, 2017.

50. Gray KE, Schiff MA, Fitzpatrick AL, Kimura M, Aviv A and Starr JR: Leukocyte telomere length and age at menopause. Epidemiology 25: 139-146, 2014

51. Hapangama DK, Turner MA, Drury JA, Martin-Ruiz C, Von Zglinicki T, Farquharson RG and Quenby S: Endometrial telomerase shows specific expression patterns in different types of reproductive failure. Reprod Biomed Online 17: 416-424, 2008

52. Butts S, Riethman H, Ratcliffe S, Shaunik A, Coutifaris C and Barnhart K: Correlation of telomere length and telomerase activity with occult ovarian insufficiency. J Clin Endocrinol Metab 94: 4835-4843, 2009.

53. Treff NR, Su J, Taylor D and Scott RT Jr: Telomere DNA deficiency is associated with development of human embryonic aneuploidy. PLoS Genet 7: e1002161, 2011.

54. Xu X, Chen X, Zhang X, Liu Y, Wang Z, Wang P, Du Y, Qin Y and Chen ZJ: Impaired telomere length and telomerase activity in peripheral blood leukocytes and granulosa cells in patients with biochemical primary ovarian insufficiency. Hum Reprod 32: 201-207, 2017.

55. Kuhn E, Meeker A, Wang TL, Sehdev AS, Kurman RJ and Shih IeM: Shortened telomeres in serous tubal intraepithelial carcinoma: An early event in ovarian high-grade serous carcinogenesis. Am J Surg Pathol 34: 829-836, 2010.

56. Wei D, Xie J, Yin B, Hao H, Song X, Liu Q, Zhang C and Sun Y: Significantly lengthened telomere in granulosa cells from women with polycystic ovarian syndrome (PCOS). J Assist Reprod Genet 34: 861-866, 2017.

57. Wang C, Shen F, Zhu Y, Fang Y and Lu S: Telomeric repeat-containing RNA (TERRA) related to polycystic ovary syndrome (PCOS). Clin Endocrinol (Oxf) 86: 552-559, 2017.

58. Li Q, Du J, Feng R, Xu Y, Wang H, Sang Q, Xing Q, Zhao X, Jin L, He L, et al: A possible new mechanism in the pathophysiology of polycystic ovary syndrome (PCOS): The discovery that leukocyte telomere length is strongly associated with PCOS. J Clin Endocrinol Metab 99: E234-E240, 2014.

59. Li Y, Deng B, Ouyang N, Yuan P, Zheng L and Wang W: Telomere length is short in PCOS and oral contraceptive does not affect the telomerase activity in granulosa cells of patients with PCOS. J Assist Reprod Genet 34: 849-859, 2017.

60. Hapangama DK, Turner MA, Drury JA, Quenby S, Saretzki G, Martin-Ruiz C and Von Zglinicki T: Endometriosis is associated with aberrant endometrial expression of telomerase and increased telomere length. Hum Reprod 23: 1511-1519, 2008.

61. Sofiyeva N, Ekizoglu S, Gezer A, Yilmaz H, Kolomuc Gayretli T, Buyru N and Oral E: Does telomerase activity have an effect on infertility in patients with endometriosis? Eur J Obstet Gynecol Reprod Biol 213: 116-122, 2017.

62. Valentijn AJ, Palial K, Al-Lamee H, Tempest N, Drury J, Von Zglinicki T, Saretzki G, Murray P, Gargett CE and Hapangama DK: SSEA-1 isolates human endometrial basal glandular epithelial cells: Phenotypic and functional characterization and implications in the pathogenesis of endometriosis. Hum Reprod 28: 2695-2708, 2013.

63. Hanna CW, Bretherick KL, Gair JL, Fluker MR, Stephenson MD and Robinson WP: Telomere length and reproductive aging. Hum Reprod 24: 1206-1211, 2009. 
64. Kuhn E, Meeker AK, Visvanathan K, Gross AL, Wang TL, Kurman RJ and Shih IeM: Telomere length in different histologic types of ovarian carcinoma with emphasis on clear cell carcinoma. Mod Pathol 24: 1139-1145, 2011.

65. Keefe DL, Liu L and Marquard K: Telomeres and aging-related meiotic dysfunction in women. Cell Mol Life Sci 64: 139-143, 2007.

66. Kalmbach KH, Antunes DM, Kohlrausch F and Keefe DL: Telomeres and female reproductive aging. Semin Reprod Med 33: 389-395, 2015.

67. Keefe DL and Liu L: Telomeres and reproductive aging. Reprod Fertil Dev 21: 10-14, 2009.

68. Yang Q, Zhao F, Dai S, Zhang N, Zhao W, Bai R and Sun Y: Sperm telomere length is positively associated with the quality of early embryonic development. Hum Reprod 30: 1876-1881, 2015

69. Reig-Viader R, Capilla L, Vila-Cejudo M, Garcia F, Anguita B Garcia-Caldés $M$ and Ruiz-Herrera A: Telomere homeostasis is compromised in spermatocytes from patients with idiopathic infertility. Fertil Steril 102: 728-738.e1, 2014.

70. Yan L, Wu S, Zhang S, Ji G and Gu A: Genetic variants in telomerase reverse transcriptase (TERT) and telomerase-associated protein 1 (TEP1) and the risk of male infertility. Gene 534: 139-143, 2014.

71. Ferlin A, Rampazzo E, Rocca MS, Keppel S, Frigo AC, De Rossi A and Foresta C: In young men sperm telomere length is related to sperm number and parental age. Hum Reprod 28: 3370-3376, 2013

72. Thilagavathi J, Kumar M, Mishra SS, Venkatesh S, Kumar R and Dada R: Analysis of sperm telomere length in men with idiopathic infertility. Arch Gynecol Obstet 287: 803-807, 2013.

73. Prescott J, Du M, Wong JY, Han J and De Vivo I: Paternal age at birth is associated with offspring leukocyte telomere length in the nurses' health study. Hum Reprod 27: 3622-3631, 2012.

74. Moskovtsev SI, Willis J, White J and Mullen JB: Disruption of telomere-telomere interactions associated with DNA damage in human spermatozoa. Syst Biol Reprod Med 56: 407-412, 2010.

75. Baird DM, Britt-Compton B, Rowson J, Amso NN, Gregory L and Kipling D: Telomere instability in the male germline. Hum Mol Genet 15: 45-51, 2006.

76. Biron-Shental T, Wiser A, Hershko-Klement A, Markovitch O, Amiel A and Berkovitch A: Sub-fertile sperm cells exemplify telomere dysfunction. J Assist Reprod Genet 35: 143-148, 2018.

77. Vecoli C, Montano L, Borghini A, Notari T, Guglielmino A, Mercuri A, Turchi S and Andreassi MG: Effects of highly polluted environment on sperm telomere length: A Pilot Study. Int J Mol Sci 18: E1703, 2017.

78. Lafuente R, Bosch-Rue E, Ribas-Maynou J, Alvarez J, Brassesco C, Amengual MJ, Benet J, Garcia-Peiró A and Brassesco M: Sperm telomere length in motile sperm selection techniques: A qFISH approach. Andrologia 50: e12840, 2018.

79. Cariati F, Jaroudi S, Alfarawati S, Raberi A, Alviggi C, Pivonello R and Wells D: Investigation of sperm telomere length as a potential marker of paternal genome integrity and semen quality. Reprod Biomed Online 33: 404-411, 2016.

80. Mishra S, Kumar R, Malhotra N, Singh N and Dada R: Mild oxidative stress is beneficial for sperm telomere length maintenance. World J Methodol 6: 163-170, 2016.
81. Rocca MS, Speltra E, Menegazzo M, Garolla A, Foresta C and Ferlin A: Sperm telomere length as a parameter of sperm quality in normozoospermic men. Hum Reprod 31: 1158-1163, 2016.

82. Liu SY, Zhang CJ, Peng HY, Huang XQ, Sun H, Lin KQ, Huang K, Chu JY and Yang ZQ: Association study of telomere length with idiopathic male infertility. Yi Chuan 37: 1137-1142, 2015 (In Chinese).

83. Antunes DM, Kalmbach KH, Wang F, Dracxler RC, Seth-Smith ML, Kramer Y, Buldo-Licciardi J, Kohlrausch FB and Keefe DL: A single-cell assay for telomere DNA content shows increasing telomere length heterogeneity, as well as increasing mean telomere length in human spermatozoa with advancing age. J Assist Reprod Genet 32: 1685-1690, 2015.

84. Yang Q, Zhang N, Zhao F, Zhao W, Dai S, Liu J, Bukhari I, Xin H, Niu W and Sun Y: Processing of semen by density gradient centrifugation selects spermatozoa with longer telomeres for assisted reproduction techniques. Reprod Biomed Online 31: 44-50, 2015.

85. Yang Q, Luo X, Bai R, Zhao F, Dai S, Li F, Zhu J, Liu J, Niu W and Sun Y: Shorter leukocyte telomere length is associated with risk of nonobstructive azoospermia. Fertil Steril 110: 648-654.e1, 2018.

86. Heidary H, Pouresmaeili F, Mirfakhraie R, Omrani MD, Ghaedi H, Fazeli Z, Sayban S, Ghafouri-Fard S, Azargashb E and Shokri F: An association study between longitudinal changes of leukocyte telomere and the risk of azoospermia in a population of Iranian infertile men. Iran Biomed J 22: 231-236, 2018.

87. Jørgensen PB, Fedder J, Koelvraa S and Graakjaer J: Age-dependence of relative telomere length profiles during spermatogenesis in man. Maturitas 75: 380-385, 2013.

88. Pech MF, Garbuzov A, Hasegawa K, Sukhwani M, Zhang RJ, Benayoun BA, Brockman SA, Lin S, Brunet A, Orwig KE, et al: High telomerase is a hallmark of undifferentiated spermatogonia and is required for maintenance of male germline stem cells. Genes Dev 29: 2420-2434, 2015.

89. Ling X, Zhang G, Chen Q, Yang H, Sun L, Zhou N, Wang Z, Zou P, Wang X, Cui Z, et al: Shorter sperm telomere length in association with exposure to polycyclic aromatic hydrocarbons: Results from the MARHCS cohort study in Chongqing, China and in vivo animal experiments. Environ Int 95: 79-85, 2016.

90. Liu M, Hales BF and Robaire B: Effects of four chemotherapeutic agents, bleomycin, etoposide, cisplatin, and cyclophosphamide, on DNA damage and telomeres in a mouse spermatogonial cell line. Biol Reprod 90: 72, 2014.

91. Dracxler RC, Oh C, Kalmbach K, Wang F, Liu L, Kallas EG, Giret MT, Seth-Smith ML, Antunes D, Keefe DL, et al: Peripheral blood telomere content is greater in patients with endometriosis than in controls. Reprod Sci 21: 1465-1471, 2014

This work is licensed under a Creative Commons Attribution-NonCommercial-NoDerivatives 4.0 International (CC BY-NC-ND 4.0) License. 